\title{
Review
}

\section{Biosafety considerations for selectable and scorable markers used in cassava (Manihot esculenta Crantz) biotechnology}

\author{
William PETERSEN ${ }^{1}$, Paul UMBECK ${ }^{1}$, Karen HOKANSON ${ }^{2}$ and Mark HALSEY ${ }^{3 *}$ \\ ${ }^{1}$ Umbeck \& Associates, Madison, WI 53717, USA \\ ${ }^{2}$ University of Minnesota, St Paul, MN 55108, USA \\ ${ }^{3}$ Donald Danforth Plant Science Center, St Louis, MO 63132, USA
}

\begin{abstract}
Cassava is an important subsistence crop grown only in the tropics, and represents a major source of calories for many people in developing countries. Improvements in the areas of resistance to insects and viral diseases, enhanced nutritional qualities, reduced cyanogenic content and modified starch characteristics are urgently needed. Traditional breeding is hampered by the nature of the crop, which has a high degree of heterozygosity, irregular flowering, and poor seed set. Biotechnology has the potential to enhance crop improvement efforts, and genetic engineering techniques for cassava have thus been developed over the past decade. Selectable and scorable markers are critical to efficient transformation technology, and must be evaluated for biosafety, as well as efficiency and cost-effectiveness. In order to facilitate research planning and regulatory submission, the literature on biosafety aspects of the selectable and scorable markers currently used in cassava biotechnology is surveyed. The source, mode of action and current use of each marker gene is described. The potential for toxicity, allergenicity, pleiotropic effects, horizontal gene transfer, and the impact of these on food or feed safety and environmental safety is evaluated. Based on extensive information, the selectable marker genes $\mathrm{nptIl,} \mathrm{hpt}$, bar/pat, and $\operatorname{man} A$, and the scorable marker gene uidA, all have little risk in terms of biosafety. These appear to represent the safest options for use in cassava biotechnology available at this time.
\end{abstract}

Key words: cassava / biotechnology / transgenics / selectable markers / scorable markers

\section{INTRODUCTION}

Genetic engineering of cassava typically involves the introduction of a gene or genes for improved agronomic performance or enhanced nutrition. However, it is the use of selectable marker genes that permits the identification of transgenic tissues by conferring preferential growth on selective media. Scorable markers are sometimes included to easily identify tissues or plants that express the marker trait in a transgene cassette. The presence of a functional marker helps to determine if linked traits will also be present in transgenic plants derived from transformed cultures. Although many selectable and scorable markers are available, only a few have been used extensively in cassava biotechnology. They include the genes nptII (Neomycin phosphotransferase II) and hpt, (Hygromycin phosphotransferase) conferring antibiotic resistance, the herbicide tolerance gene bar/pat (Phosphinothricin acetyltransferase), and the positive selection marker gene manA (phosphomannose isomerase). The preferred reporter genes used are uidA, ( $\beta$-glucuronidase, GUS), $l u c$, (luciferase), and $g f p$ (green fluorescent protein). Most of these genes have been approved for use in other crops and their protein products are well characterized. Regulation of genetically engineered crops requires extensive efficacy testing, field testing, environmental monitoring and biosafety assessments before commercial release. The purpose of this paper is to review the current environmental, food and feed safety considerations of cassava markers and to provide a summary of the literature useful for project planning and/or regulatory submissions.

\footnotetext{
* Corresponding author: MHalsey@danforthcenter.org
} 


\section{CURRENT SCOPE OF WORK IN CASSAVA BIOTECHNOLOGY}

Cassava is a staple crop in tropical regions and is a significant source of dietary calories (Westby, 2002). The ability to tolerate poor soils and drought conditions and persist in the soil for long periods makes cassava a reliable food source on marginal agricultural lands (Fregene and Puonti-Kaerlas, 2002). Traditional breeding of cassava is hampered by a high degree of heterozygosity, irregular flowering, low seed set, and variable germination rates (Jennings and Iglesias, 2002). Because cassava is grown on many small farms with diverse environments, it is unlikely the current breeding efforts will sustain future crop improvement needs (Taylor et al., 2004).

Over the past decade, genetic engineering techniques have been developed for cassava. The somewhat recalcitrant nature of cassava hampered early efforts to develop regeneration and transformation protocols (González et al., 1998). However, in 1996, three research groups were successful at producing transgenic cassava plants, Schöpke et al. (1996), Raemakers et al. (1996), and Li et al. (1996). These original techniques and more recent transformation protocols are being applied to the production of transgenic cassava with enhanced resistance to insect pests and viral diseases, enhanced nutritional qualities, reduced cyanogenic content and modified starch characteristics. Proof-of-concept field trials are being initiated to test the agronomic performance of introduced genes. The ground work needed for eventual farm scale release is being planned. Adapting the transformation technology to farmer-preferred cultivars will be important for product acceptance. Equally important is the development of the intellectual property and regulatory infrastructure needed before transgenic cassava can be fully exploited. A thorough review of cassava biotechnology was recently published by Taylor et al. (2004).

In order to facilitate decision making on the biosafety of transgenic cassava lines, the selectable markers used in cassava biotechnology are reviewed and the biosafety aspects of each marker evaluated.

\section{THE ROLE OF SELECTABLE AND SCORABLE MARKERS IN PRODUCTION OF TRANSGENIC PLANTS}

At the cellular level, current DNA transfer technologies are inefficient. The success of introducing foreign DNA is estimated to be one in one thousand to one in one million cells treated (Brasileiro and Aragão, 2001). Plant biotechnologists have relied upon the use of selectable markers to identify and recover the rare transformation events expressing a functional marker trait and, potentially, the linked trait of agronomic interest. Efficient selection of cells containing the introduced DNA allows for development of proficient transgenic plant production systems. Almost fifty different selection systems have been reported but few have reached practical application (Miki and McHugh, 2004).

The most successful and commonly used selectable marker systems rely on plant cell growth inhibitory substances incorporated into the tissue culture medium. The introduction of a gene encoding a detoxifying enzyme into the cell's genome enables these cells to survive. Traits linked to the selectable marker are also incorporated into the cells but must be screened for integrity and function. Antibiotic and herbicide resistance selectable markers are the most widely used in selection systems (Goldsbrough, 2001).

Scorable markers, or reporter genes, typically allow for visualization of the cells, tissues or plants expressing the gene, and may be used to develop and monitor plant transformation processes, to assess gene expression levels and to follow the integrated trait in breeding programs. The most frequently used reporter genes are uidA $\beta$-glucuronidase (GUS, Gilissen et al., 1998), gfp Green Fluorescent Protein (GFP, Richards et al., 2003), and the luciferase gene (luc) from firefly Photinus pyralis (Millar et al., 1992).

A brief review of cassava transformation systems and biosafety of the markers used follows.

\section{COMMON SELECTABLE AND SCORABLE MARKERS USED IN CASSAVA BIOTECHNOLOGY}

The selectable markers and reporter genes used in cassava transformation protocols were recently reviewed by Taylor et al. (2004). The nptII gene confers resistance to the antibiotics kanamycin, paromomycin and G418. The nptII gene is preferentially used for cassava transformation by several labs. Another antibiotic resistance gene, $h p t$ is also used. The bar gene, which confers resistance to herbicides containing phosphinothricin, has been used both as a selectable marker and as a gene of interest. The manA gene has been used successfully in a positive selection scheme to recover transgenic cassava plants, but its adoption has not been wide spread. The visual reporter genes, uidA, luc, and $g f p$ have all been used in cassava transformation. The luc gene has also been utilized as a visual selectable marker for the recovery of transgenic plants (de Vetten et al., 2003; Raemakers et al., 1996). 
Review: Biosafety considerations for selectable and scorable markers used in cassava biotechnology

\section{ENVIRONMENTAL SAFETY CONSIDERATIONS}

The two most common environmental concerns associated with any genetically engineered crop are the potential to affect nontarget organisms and the potential to increase the weediness or invasiveness of the crop plant or of its compatible wild relatives (Hails, 2000; NAS, 2000; 2002; Wolfenbarger and Phifer, 2000). Most selectable or scorable marker genes used in plant biotechnology, including those commonly used in cassava transformation, are not expected to raise these concerns.

Nontarget organism effects are of concern when there is reason to suspect that the introduced trait could have a substantial adverse effect on such organisms. For example, a gene inserted for resistance to a target crop pest might harm related nontarget insects. The marker genes used in cassava transformation include those for antibiotic resistance, for herbicide tolerance, for substrate utilization, and for visual selection. There is no reason to expect that any of these genes expressed in the plant will have significant effects on nontarget organisms. Toxicity, allergenicity, and substantial equivalence of these marker genes, as well as their use in other crops, are described below: many of these assessments are also relevant to the potential nontarget effects of these genes.

The genes discussed here are also not expected to result in increased weediness or invasiveness of cassava or its wild relatives. Traits raising this concern are typically those which increase the fitness of the plant by conferring resistance to biotic or abiotic stress, and which may thus affect seed production, survival, or persistence. There is no reason to expect that the antibiotic resistance genes, the mannose metabolism gene, or the visual reporter genes used in cassava transformation would alter the fitness of the cassava plant or any of its relatives. The potential fitness effect of the bar gene for phosphinothricin herbicide tolerance, in the presence of the herbicide, is discussed in the relevant section below.

Pleiotropic effects and Horizontal Gene Transfer (HGT) are additional concerns, based on potential effects to the environment and food and feed safety. When the genetic makeup of an organism has been altered by conventional breeding or recombinant DNA (rDNA) techniques, there is the potential for unintended beneficial or deleterious effects. These pleiotropic effects may alter the fitness, environmental impact, or food and feed safety characteristics of the organism. Using GeneChip technology, Ouakfaoui and Miki (2005) monitored 24,000 genes in transgenic and non-transgenic Arabidopsis thaliana (L.) Heynh plants grown in ideal conditions and under conditions of abiotic stress. They concluded that transgenic Arabidopsis plants expressing the marker genes $n p t I I$ and uidA were phenotypically normal and global gene expression patterns were similar to that of non-transgenic controls. Pleotropic effects in transgenic plants have recently been reviewed by the EU-sponsored ENTRANSFOOD Thematic Network (Cellini et al., 2004). HGT between the transformed plants and soil microflora, gut bacteria or cells of organisms ingesting the plants may allow the recipient cell or organism to express a protein with unintentional effects (Van den Eede et al., 2004). Neither pleiotropic effects nor HGT are considered likely. The potential for each is addressed in the discussion of the individual marker genes in subsequent sections.

\section{BIOSAFETY EVALUATION OF SPECIFIC GENES}

The main biosafety concerns for selectable and scorable marker genes used in genetic engineering of cassava may thus be placed into four main areas: (1) acute toxicity, (2) allergenicity, (3) pleiotropic effects, and (4) consequences of any HGT of the introduced rDNA.

All foods from plants and animal sources contain DNA. There are no reports of DNA being toxic or allergenic. Therefore, it is expected that rDNA by itself in transgenic plants would not present any health risks. The United States Environmental Protection Agency (EPA) has granted a blanket exemption for all nucleic acids (Federal Register 40 CFR 174.475).

The vast majority of genes introduced into plants encode proteins (Astwood and Fuchs, 1996). In general, proteins are not toxic (Jones and Maryanski, 1991). However, a few proteins are known to act via acute mechanisms and at very low dose levels to create toxic reactions (Sjoblad et al., 1992). Animal model feeding studies are conducted to determine the toxicity potential of proteins. A broad range of treatment dosages are used to gather information about the physiological affects of a protein. Such evaluations include exposure levels many times the normal consumption rate in order to determine the health and safety limits of the protein.

Novel proteins from transgenic plants are also assessed for allergenicity potential. Over the years, it has been determined that proteins from food that are allergenic share common physical and chemical characteristics. They include resistance to proteolysis, protein processing stability, abundance and possible glycosylation (Astwood and Fuchs, 1996). A draft annex by the Codex Alimentarius Commission Alinorm 03/34 (2003) recommended a step-wise approach to assess the likelihood of a new 
recombinant protein being a food allergen. Newly expressed proteins in recombinant plants should be evaluated for the potential that certain individuals may already be sensitive to the protein or that the proteins may induce new allergic reactions. The process of evaluation takes into consideration the following: (1) whether the gene donor source is a known allergen; (2) protein sequence similarity to that of known food allergens; (3) the physical characteristics of the protein, such as degree of degradation due to heat instability, acid and enzyme treatment; (4) sera screening, if the protein source is a known allergen; and (5) any effects of food processing on the presence of the protein in the final product.

The introduction of new genetic material into plant genomes also has the potential to cause unintended changes in phenotype or composition, due to pleiotropic effects (multiple phenotypic effects due to a single gene) or to disruption or alteration of the genome at the site of insertion. As with random mutation, most unintended changes caused by deliberate insertions of genetic material will be, at best, neutral to the plant and a significant improvement in ecological fitness or substantial compositional changes would be extremely rare. However, in order to identify any meaningful unintended changes, transgenic plants in development are typically observed for morphological changes and subjected to compositional analysis to establish substantial equivalence to the parental (non-transgenic) crop plant (Haslberger, 2003; Stewart et al., 2000). The collection of such information is used to establish the health and safety characteristics of the new phenotype(s). The insertion site of a transgenic plant submitted for advanced testing is also carefully characterized for its potential to affect other functions. It should be noted, however, that insertional effects are related to the specific transformation event, and not to the function of the gene that has been inserted.

The potential for HGT of marker genes from transgenic plants to intestinal micro-flora, human cells or soil bacteria has also been investigated (Miki and McHugh, 2004). Under ideal laboratory conditions, HGT can be forced from plants to bacterial cells at very low frequencies, using homologous transformation and rescue of mutant alleles. Thus, these studies do not show spontaneous and complete HGT under natural conditions; no transfer of an intact functional gene has been demonstrated to date. Data on gene transfer to micro-flora or mammalian cells outside of the laboratory setting is lacking (Advisory Committee on Releases to the Environment, 2002; Smalla et al., 2000). Genes that have been designed for use in plant transformation are also typically modified to use plant-preferred codons. A modified gene transferred with a plant promoter system from a plant to a microorganism is predicted to express poorly (ACRE, 2002). Although there seems little likelihood of significant HGT in nature, the current state of genetic knowledge indicates that such transfers are not impossible, and we must assume that they are possible, albeit at a very low frequency. If a gene is indeed transferred, expressed, and the recipient organism replicates, the potential health or environmental impact of HGT can be assessed for each gene. For example, HGT of the $n p t I I$ or $u i d A$ genes would be of limited consequence due to the natural presence of high levels of these genes within bacterial populations of the digestive tract (Gilissen et al., 1998; Nap et al., 1992) and in the environment. The ENTRANSFOOD assessment has described three categories of antibiotic resistant marker genes, according to the level of consequence of any possible HGT (Van den Eede et al., 2004). The antibiotic resistance genes discussed here fall into the lowest risk class, Category I. By this classification, genes that are already widely distributed in soil and enteric bacteria, and that confer resistance to antibiotics having only limited use in human and veterinary medicine.

Specific assessments of the biosafety of selectable and scorable markers used in cassava biotechnology follow.

\section{SELECTABLE MARKERS}

\section{nptII: Neomycin phosphotransferase II (NPTII)}

Synonyms: neo, aminoglycoside 3'-phosphotransferase II $=$ APH[3] II.

Source: Isolated from the Tn5 transposon of Escherichia coli (Migula) Castellani and Chalmers (Beck et al., 1982).

Mode of action: Aminoglycosides such as kanamycin A, $\mathrm{B}$, and $\mathrm{C}$, neomycin, paramomycin and geneticin (G-418) contain a 3'-hydroxyl group on the amino-hexose structure of the antibiotics. NptII catalyses the transfer of the -phosphate group of Adenine Triphosphate to the 3'hydroxyl group. This prevents the antibiotic from binding to the 30s ribosomal subunit and thus inhibits protein synthesis (Brasileiro and Aragão, 2001; EFSA, 2004; Miki and McHugh, 2004).

Current use in cassava research: The use of nptII has been published by several research groups (González et al., 1998; Raemakers et al., 1997; 2001; Sarria et al., 2000; Schöpke et al., 1996; Siritunga and Sayre, 2003). Paromomycin is the commonly used selective agent. Plants containing nptII have been approved by the 
Colombian government for small, contained field trials in CIAT (Chavarriaga, 2005).

Use in other crops, status of commercialization: $n p t I I$ was the first selectable marker used for plant transformation (Bevan et al., 1983; Fraley et al., 1983; Herrera-Estrella et al., 1983) and is the most widely used for production of transgenic plants for research and commercialization (European Food Safety Authority, 2004). Information gathered from the U.S. Department of Agriculture, Animal and Plant Health Inspection Service (APHIS) database on transgenic field permits and notifications dating back to 1987 indicate that there have been over 3,900 field tests with 71 different agronomic and horticultural crops containing the nptII gene. Crops that contain the nptII gene that have been approved for commercial release in the United States include (crop: number of approvals) Chicory (Cichorium intybus L.):1, Corn (Zea mays L.):2, Cotton (Gossypium hirsutum L.):3, Flax (Linum usitatissimum L.):1, Papaya (Carica papaya L.):1, Potato (Solanum tuberosum L.):4, Rape (Brassica napus napus L.):3 and Squash (Curcubita spp.):1 (Information Systems for Biotechnology: Field Test Releases in the U.S. Updated 12/22/2004).

Safety assessment of nptII: As the first and most commonly used selectable marker, the biosafety of nptII and the protein NPTII may also be the most extensively studied. Over the past 12 years there have been numerous studies on the safety of consuming the rDNA which encodes NPTII, studies conducted on the toxicity and allergenicity of the protein, evaluation of risks associated with horizontal gene transfer (see below) and the protein effects on enteric bacteria and therapeutic antibiotic use (Nap et al., 1992; Fuchs et al., 1993; Redenbaugh et al., 1994; European Federation of Biotechnology, 2001; European Food Safety Authority, 2004). The amount of $n p t I I$ DNA and protein that consumers are exposed to is negligible compared to the natural background levels. The protein is not an acute toxin, even when tested at feeding rates a million times higher than expected exposure levels (5g.kg-1 body weight in mice (Mus spp.), Fuchs et al., 1993). Nor does it have properties associated with known food allergens (Taylor et al., 1987). The NPTII protein is rapidly degraded in simulated gastric fluids and simulated intestinal fluids (Australia New Zealand Food Authority, 2001). Protein and DNA sequence comparisons in four separate databases (GenBank, EMBL, PIR 29, and Swiss-Prot) showed that NPTII protein does not have significant similarity to any proteins listed as food allergens or toxins (Food and Drug Administration Center for Food Safety and Applied Nutrition Office of Premarket Approval, 1998). The use of NPTII in transgenic plants poses less risk to the use of therapeutic antibiotics in humans or in animals (Nap et al., 1992) than that from naturally occurring bacterium to bacterium transfer of antibiotic resistance genes.

The use of $n p t I I$ and the protein has been approved by the U.S. Food and Drug Administration (1994). A workshop of the World Health Organization (1993) has concluded that the nptII marker gene poses no risk to human health. The Nordic Working Group on Food Toxicology and Risk Assessment issued a report recommending that the nptII marker gene is acceptable in the genetic engineering of food plants (Kärenlampi, 1996). In 2004, the Scientific Panel on genetically modified organisms (GMO Panel) of the European Food Safety Authority (EFSA) concluded that after 13 years of safe use and careful evaluation, there is no rationale for restricting the use of $n p t I I$ as a selectable marker for either field studies or commercialization of crop plants containing the protein (European Food Safety Authority, 2004).

Pleiotropic effects: Enhancement of physiological fitness due to pleiotropic effects of $n p t I I$ has not been documented (Miki and McHugh, 2004), and expression of nptII in Arabidopsis had no functional effect on the expression of 24,000 other genes studied (Ouakfaoui and Miki, 2005). Potential risks of horizontal gene transfer: The nptII gene is ubiquitous in the environment and in gastrointestinal bacteria. The consequences of HGT of the nptII gene from a transgenic plant to gastrointestinal or soil bacteria would be negligible (Jelenic, 2003; Van den Eede et al., 2004).

\section{bar/pat: phosphinothricin acetyl transferase (PAT)}

Source: The bar gene was isolated from Streptomyces hygroscopicus (Streptomyces hygroscopicus subsp. hygroscopicus (Jensen) Waksman and Henrici) (Thompson et al., 1987). The pat gene was isolated from Streptomyces viridochromogenes (Streptomyces viridochromogenes (Krainsky) Waksman and Henrici) (Wohlleben et al., 1988).

Mode of action: Phosphinothricin (L-PPT), the active ingredient of herbicides such as Basta ${ }^{\mathrm{TM}}$, Liberty ${ }^{\mathrm{TM}}$ and Herbiace $^{\mathrm{TM}}$, inhibits glutamine synthetase. The action results in the accumulation of lethal levels of ammonia in susceptible plants within hours of application (Canadian Food Inspection Agency, 1998). In the presence of acetylCoA, PAT enzymes (from bar/pat) catalyze the acetylation of the free amino group of L-PPT to yield Nacetyl-L-PPT, restoring glutamine synthetase activity. Both forms of the enzyme are highly specific for L-PPT and do not acetylate other L-amino acids (ACRE, 2002). 
Current use in cassava research: The use of the bar gene as a selectable marker and for producing herbicide resistance cassava plants has been reported by Raemakers et al. (1997, 2001) and Sarria et al. (2000).

Use in other crops, status of commercialization: The bar gene was first shown to be effective as a plant selectable marker by DeBlock et al. (1989). It has become the most extensively used of the herbicide resistance selectable markers (Miki and McHugh, 2004). Information collected from the AGBIOS database (http://www.agbios. com/dbase.php) indicated that 22 food and feed approvals were obtained for the bar/pat gene in seven different crop plants including sugarbeet (Beta vulgaris L. subsp. vulgaris), B. napus, chicory, soybean (Glycine max (L) Merr.), cotton, rice (Oryza sativa L.) and corn.

Safety assessment of bar/pat: Expression of the bar/pat gene is not injurious to plants (OECD publication No. 11, 1999). PAT, the enzyme from bar/pat, has high substrate specificity. Human exposure to PAT protein is not new. The bar/pat genes were isolated from common soil bacteria. The bar gene and the enzyme it encodes are present in the environment, with no known adverse effects on humans and animals (Canadian Food Inspection Agency, 2004).

The PAT protein is not a known allergen and does not exhibit any of the characteristics known for food allergens. The PAT protein showed no significant nucleotide sequence similarity with any known toxins or allergens. Unlike most allergens, there are no glycosylation sites on the PAT protein and gastric digestion of the protein was rapid (CFIA, 1998; OECD, 1999). The U.S. EPA concluded that "the potential for the PAT protein to be a food allergen is minimal" (EPA, 1997).

An acute intravenous mouse toxicity study with PAT protein administered at a rate of $10 \mathrm{mg} \cdot \mathrm{kg}^{-1}$ body weight produced no treatment related adverse effects. A subchronic rodent study further supports the contention that the PAT enzyme is safe. Other studies with canaries (Serinus canarius L.), beneficial insects and pollinators help to demonstrate the safety of the PAT protein. Governmental regulatory authorities in the United States, Canada, Japan and European Union have issued decisions that the presence of the PAT protein in plants does not render them unsafe for consumption as food or feed (OECD publication No. 11, 1999).

The possibility of increased weediness due to phoshinothricin herbicide tolerance conferred by the bar/ pat gene is of concern only if the following conditions are met: (1) the herbicide in question must be critical for control of the crop plant or its compatible wild relatives in agricultural settings or in other managed ecosystems,
(2) the expression of herbicide tolerance from the marker gene must be sufficient to confer practical tolerance to herbicide application as used in the field. Even if these conditions were true, cassava does not survive well outside of agricultural settings (Olsen and Schaal, 1999), and may be controlled by several common nonphosphinothricin herbicides (e.g., glyphosate, paraquat), or by cultivation. Thus, there is little concern for increased weediness from the use of the bar/pat gene as a selectable marker in cassava.

Pleiotropic effects: None reported.

Potential risks of horizontal gene transfer: The bar/pat gene is naturally occurring in the soil. It is much more likely that HGT will occur between bacteria than from transgenic plants to bacteria. In the rare event that this should occur, the plant preferred codons of bar/pat gene in the plant would have low or no expression in bacteria (ACRE, 2002).

\section{hpt: Hygromycin phosphotransferase}

Synonyms: hph, aphIV or aph4, aminoglycoside 4'phosphotransferase, APH4 for the protein.

Source: The hpt gene, which confers resistance to the antibiotic Hygromycin B, was isolated from a plasmid found in E. coli W677 (Kuhstoss and Rao, 1983; Rao et al., 1983).

Mode of action: APH4, the protein product from $\mathrm{hpt}$, catalyzes the phosphorylation of the 4-hydroxyl group of Hygromycin B, rendering it biologically inactive (Pardo et al., 1985).

Current use in cassava research: Selection based on the use of hpt/ hygromycin has been reported by several labs (Raemakers et al., 2001; Zhang et al., 2000a). The efficiency of hygromycin-based selection, as compared to nptII, seems to vary depending on the variety and transformation system being used (Chavarriaga, 2005; Taylor et al., 2004).

Use in other crops, status of commercialization: Since the first reported use of the hpt gene as a selectable marker in 1985, it has become the second most frequently used antibiotic selectable marker for the production of transgenic plants (Miki and McHugh, 2004; Waldron et al., 1985). It has been approved in nearly 350 U.S. field tests in 31 different crops (Information Systems for Biotechnology, 2004).

Safety assessment of $\boldsymbol{h p t}$ : Hygromycin B is not used for clinical purposes with humans. The antibiotic is detoxified by the hpt gene protein. The APH4 enzyme is highly specific for a limited number of antibiotics including hygromycin $\mathrm{B}$, hygromycin $\mathrm{B}_{2}$, destomycin $\mathrm{A}$ and destomycin $\mathrm{B}$. 
Review: Biosafety considerations for selectable and scorable markers used in cassava biotechnology

The APH4 enzyme has no effect on aminocyclitol or aminoglycoside antibiotics such as gentamycin, neomycin and spectinomycin (EPA, 2004a).

The protein APH4 is not acutely toxic in animal studies. Mice fed APH4, $779 \mathrm{mg} \cdot \mathrm{kg}^{-1}$ body weight showed no observable differences when compared to control mice. Database analysis reveals no similarity to known toxic proteins or allergens. The hpt gene was isolated from $E$. coli, which is not a known source of food allergens. The protein is not naturally glycosylated in plants. The APH4 protein is rapidly degraded in simulated gastric fluid. In 2004 the U.S. EPA granted an exemption from the requirement of a tolerance for residues of the hygromycin B phosphotransferase (APH4) marker protein (EPA, 2004a). European Food Safety Authority (2001) recommended that no restrictions be placed on the use of the hpt gene as a selectable marker, whether for field testing or commercialization.

Pleiotropic effects: None reported.

Potential risks of horizontal gene transfer: The antibiotic resistance APH4 protein is wide spread in the environment and in human and animal digestive systems (Office of the Gene Technology Regulator, 2003). Genes encoding APH4 have been isolated from Klebsiella pneumoniae (Gritz and Davies, 1983) and S. hygroscopicus (Leboul and Davies, 1982; Malpartida et al., 1983) in addition to the $E$. coli source. The extremely rare possible transfer of the hpt gene from a transgenic plant to a bacterium would have little effect in light of the natural occurrence of the gene and protein (Van den Eede et al., 2004).

\section{manA: Phosphomannose isomerase (PMI)}

Synonyms: B1613, ManA, mannose-6-phosphate isomerase, phosphohexoisomerase, phosphohexomutase, Dmannose-6-phosphate ketol-isomerase.

Source: The manA gene used in plant transformation selection protocols was originally isolated from $E$. coli K12 (Miles and Guest, 1984).

Mode of action: The PMI enzyme allows for the conversion of mannose-6-phosphate, a sugar not used by plant cells, into fructose-6-phosphate, a sugar that can be immediately metabolized. Mannose can therefore be used as a sole carbon source for plant cell culture when the manA gene is present in the plant's genome (Miki and McHugh, 2004).

Current use in Cassava research: The first report of the manA selectable marker being used in cassava was reported by Zhang et al. (2000b).

Use in other crops, status of commercialization: The manA/PMI selection system has been used in many crops such as sugarbeet, corn, wheat (Triticum aestivum L.), rice, B. napus, tomato (Lycopersicon esculentum Mill.) and barley (Hordeum vulgare L.) (Privalle et al., 2000). More recently, there have been reports of manA/PMI selection in bentgrass (Agrostis avenacea J.F. Gmel), apple (Malus domestica Borkh.), onion (Allium cepa L. var. cepa), hemp (Cannabis sativa L.) and Blackgram (Vigna mungo (L.) Hepper var. mungo).

Safety assessment of PMI: The safety of PMI has been evaluated by researchers at Syngenta Seeds, Inc. (Privalle, 2002; Privalle et al., 2000; Reed, 2001) and the EPA (2004b). A summary of the results and conclusions follows:

- The protein was found to be non-toxic in an acute toxicity study. Mice were fed PMI protein equivalent to $3.03 \mathrm{gm} \cdot \mathrm{kg}^{-1}$ of body weight. No clinical signs of toxicity were detected 14 days post dosing in either the test mice or in the controls. The EPA concluded that PMI could be considered nontoxic. In addition, amino acid sequence comparisons did not indicate similarity to any known toxic proteins.

- Plants expressing the manA gene were tested for changes in mannose-associated biochemistry. No detectable differences were found between transgenic plants containing PMI and nontransgenic controls.

- PMI does not possess the characteristics of known food allergens. There was no sequence similarity to known allergens. The transgenic-plant-derived PMI did not contain glycosylation patterns similar to allergens. Analysis of the transgenic plants did not detect any changes to the glycoprotein profiles.

- PMI is readily digested. In vitro digestibility studies showed that PMI is digested immediately in simulated mammalian gastric fluids and within two minutes in simulated intestinal fluid. The rapid digestion of the protein indicates little risk of PMI being an oral allergen. The U.S. EPA established an exemption from the establishment of residue tolerances for PMI when used in transgenic plants (EPA, 2004b).

Pleiotropic effects: There were no significant differences in a comparison of transgenic maize lines and their isoline, non-transgenic counterpart on the basis of yield and multiple agronomic characteristics such as plant height, stalk quality, emergences, etc.

Potential risks of horizontal gene transfer: There is little risk associated with the possible rare transfer of a plant derived transgene into the environment. Phosphomannose isomerase is common in nature and in humans. PMI has been isolated from yeast, bacteria, pigs 
and humans (Privalle et al., 2000). PMI is an essential enzyme in nature and is involved with routine physiological functions. Humans are exposed to PMI from internal sources and from many foods they consume (EPA, 2004b).

\section{REPORTER GENES}

\section{uidA (gus): $\beta$-D-glucuronide glucuronoso-hydrolase (GUS)}

Synonyms: $\beta$-D-glucoronidase, $\beta$-glucoronidase.

Source: From E. coli K12.

Mode of action: $\beta$-glucuronidase catalyses the hydrolysis of glucuronides. Numerous chromogenic and fluorogenic substrates are available for quantitative analysis. 5bromo-4-chloro-3-indolyl glucuronide (X-gluc) is used for histological localization (Jefferson, 1989).

Current use in cassava research: The uidA scorable marker has been used in cassava biotechnology by several labs (González et al., 1998; Sarria et al., 2000; Schöpke et al., 1996). Plants carrying a uidA-intron gene have been released for small, contained field trials in CIAT (Cali, Colombia) (Chavarriaga, 2005).

Use in other crops, status of commercialization: The uidA ( gus) gene is used extensively in transgenic plant research; uidA is the most frequently used reporter gene (Miki and McHugh, 2004), having been involved in over 1,000 field tests with 50 different organisms (Information Systems for Biotechnology, 2004). The uidA gene has been approved for commercial use in Sugarbeet (1), Papaya (1), Soybean (2) and Cotton (1).

Safety assessment of uidA/GUS: $E$. coli bacteria are common in vertebrate intestinal tracts and in soil and water. The expression of E. coli GUS occurs naturally in the human digestive tract. GUS is also present in human intestinal epithelial cells and numerous foods, including raw apples and oysters. The presence of GUS from transgenic plants in foods is not thought to be a health risk or have the potential to be harmful (Gilissen et al., 1998). The GUS protein has no similarity to known toxins. An acute toxicity study with mice indicated that GUS protein is not toxic. Mice were dosed with GUS at 40, 100 and $400 \mathrm{mg} \cdot \mathrm{kg}^{-1}$ body weight. No adverse treatment related effects were observed over the 8-9 days of the study (Monsanto Company, 2003). GUS does not have any of the characteristics known to occur in protein toxins or food allergens.

The digestibility of GUS was assessed by simulated mammalian gastric fluid (SGF) and simulated mammalian intestinal fluid (SIF) assays. GUS was undetectable by either western blot analysis or enzymatic activity assay after just 15 seconds exposure to the SGF. After two hours exposure to SIF, enzymatic GUS activity was reduced by $91 \%$. GUS consumed by humans is readily digested (Food Standards Australia New Zealand, 2002).

Pleiotropic effects: None reported. Expressing the protein of $E$. coli-derived uidA in transgenic plants may cause hydrolysis of glucoronides present in the plant. Toxic effects are not expected from metabolites of transgenic GUS activity in plants (Gilissen et al., 1998). As with nptII, Ouakfaoui and Miki (2005) reported no phenotypic or genetic expression changes of 24,000 genes in transgenic Arabidopsis plants containing the uidA gene. Potential risks of horizontal gene transfer: As with the other markers, genes originally isolated from $E$. coli (nptII, hph and manA), the uidA gene and the GUS enzyme are widely distributed in the environment, are present in the intestinal tract of vertebrates, including man and are present in food. The extremely remote possibility of the uidA gene transferring from GM cassava into the environment does not present an additional health or safety risk to humans.

\section{gfp: Green Fluorescent Protein (GFP)}

Source: From jelly-fish (Aequorea victoria) (Chalfie et al., 1994).

Mode of action: Absorbs light at wavelengths of 395 or $470 \mathrm{~nm}$; excites a chromophore (-hydroxybenzylideneimidazo-lidinone), which emits light at $509 \mathrm{~nm}$ (Pang et al., 1996).

Current use in cassava research: Green fluorescent Protein has been used to visualize the development of early transgenic tissues in cassava transformation (Laminski et al., 2002) and in stable events (Taylor, 2005). Use in other crops, status of commercialization: There have been 56 field trials in the U.S. with crops containing $g f p$. They include the crops barley (5), bermudagrass (Cynodon dactylon (L.) Pers. var. dactylon) (2), corn (32), cotton (1), grapefruit (Citrus $\times$ paradise Macfad.) (1), onion (2), B. napus (7), rice (1) and tobacco (Nicotiana tabacum L.) (2) (Information Systems for Biotechnology, 2004).

Safety assessment of GFP: Richards et al. (2003) made an assessment on the food safety of GFP. Young male rats (Rattus spp.) fed 26 days on a diet supplemented with either purified GFP (1 mg.d $\left.\mathrm{d}^{-1}\right)$ or transgenic B. napus expressing GFP, did not differ in survival or growth rates as compared to the controls for each treatment. Organ weights (small and large intestine, heart, liver, lung, stomach, kidney, spleen and testis) from the treatment rats 
Review: Biosafety considerations for selectable and scorable markers used in cassava biotechnology

were comparable to those of the control. GFP from the transgenic Brassica napus was undetectable in the rat tissues, serum or feces. GFP was detectable in the large and small intestines and feces from rats fed GFP at $1 \mathrm{mg} . \mathrm{d}^{-1}$. Quantitative ELISA assays indicated the GFP levels were $0.1 \%$ or less than the amount administered. Amino acid sequence analysis of the GFP protein did not indicate significant similarity to know food allergens. The GFP used in this study had been modified with an endoplasmic reticulum targeting sequence. The analysis revealed similarity to secretory targeting sequence from agglutinin, a food allergen from peanuts (Arachis hypogaea L.) but these targeting sequences are cleaved before the protein is folded (Richards et al., 2003).

Purified GFP in either an applesauce matrix or within transgenic $B$. napus was undetectable after five minutes of simulated digestion in hydrochloric acid $(\mathrm{HCl})$ and porcine pepsin. However, GFP was detectable from the $\mathrm{GFP}(+)$ applesauce treatment after 20 minutes of $\mathrm{HCl}$ treatment minus the pepsin. Others have reported that GFP is a very stable protein (Chalfie, 1995). The preliminary conclusion of the Richards (2003) study was that GFP had a low risk of being allergenic and was not toxic in a rat feeding study.

Pleiotropic effects: High GFP expression in Arabidopsis tissues may have interfered with plant regeneration. It was postulated that the protein may be mildly toxic to plant cells at high concentrations (Haseloff and Amos, 1995).

Potential risks of horizontal gene transfer: None reported in the scientific literature reviewed.

\section{Iuc: Luciferase (LUC)}

Synonyms: Photinus-luciferin: oxygen 4-oxireductase. Source: The luciferase gene, $l u c$, was isolated from the firefly Photinus pyralis (Ow et al., 1986).

Mode of action: The luc gene encodes a protein called luciferase, which is functional without any posttranslational processing. In the presence of D-luciferin, $\mathrm{O}_{2}$ and ATP, luciferase catalyzes the mono-oxygenation of the substrate D-luciferin, forming an enzyme-bound luciferyladenylate complex with subsequent oxidative decarboxylation producing $\mathrm{CO}_{2}$, oxyluciferin, AMP and light (Marker Gene Technologies, Inc.).

Current use in cassava research: $l u c$ has been used as both a reporter gene and as a means for visible selection of transgenic cells and subsequent plant regeneration (de Vetten, 2003; Raemaker et al., 1996; 2001). Cassava containing $l u c$ has been approved for field trials in the U.S. Virgin Islands (Information Systems for Biotechnology, 2004).
Use in other crops, status of commercialization: The luc gene is used primarily for transient expression studies. There are only a few field trials in the U.S. listed in the USDA APHIS database. They include cassava (2), corn (21), soybean (4) and wheat (3) (Information Systems for Biotechnology, 2004).

Safety assessment of Luc: No safety assessments were found in the literature on the LUC protein.

Pleiotropic effects: None reported in the scientific literature reviewed.

Potential risks of horizontal gene transfer: None reported. However, bioluminescence is common in nature.

\section{THE POTENTIAL OF MARKER-FREE TECHNOLOGIES IN TRANSGENIC CASSAVA PRODUCTION}

As documented above, transgenic crops containing selectable marker genes and reporter genes have been approved for food and feed purposes. Safety assessments on $n p t I I$, bar/pat, hpt, manA, uidA and $g f p$ have concluded that the genes and the proteins they encode for are safe. For these well characterized genes and gene products, there may not be a compelling biosafety reason to eliminate the markers from the transgenic crops. All the current marker-free strategies are difficult to implement and inefficient compared to transformation strategies that leave the marker genes in the plant (Miki and McHugh, 2004). The methods described may not be equally suited for all plants or transformation techniques (Goldsbrough, 2001). Marker-free technologies can be useful for applications when marker safety is in question or when the researchers are interested in stacking multiple genes. Minimizing the amount of rDNA in the final product may simplify the regulatory approval process and increase consumer acceptance. Below is a brief summary of marker free technologies:

- No selection: High efficiency plant transformation coupled with advanced plant analysis can allow the recovery of transgenic plants without the use of marker genes and chemical based selection (de Vetten et al., 2003).

- Co-transformation: In sexually reproduced crops, it is possible to segregate away selectable markers (Taylor et al., 2004). Transformation techniques that enhance the integration of the marker gene in separate loci from that of the gene of interest are used (Brasileiro and Aragão, 2001). This enables the segregation of the selectable marker gene away from the gene of interest in the following 
generation and recovery of marker-free plants (Matthews et al., 1999). This technique is of limited utility in vegetatively propagated crops such as cassava, especially when farmer-preferred cultivars are used in the transformation process. In addition, this process is inefficient in that several fold more transgenic plants are needed in order to recover the marker-free plants (Goldsbrough, 2001).

- Site-specific recombination system: These systems rely on the introduction of the marker gene flanked by specific DNA sequences. Expression of a recombinase enzyme then catalyzes the recombination of the flanking sites, eliminating the marker gene from the genome. Common recombination systems are cre/lox, flp/frt and $R / R S(\mathrm{Ow}, 2002)$. These systems rely on co-transformation, re-transformation or crosses to a plant containing the gene expressing the recombinase enzyme in order to excise the marker gene (Goldsbrough, 2001). Kopertekh et al. (2004) used a Potato Virus-X based vector to transiently express cre in transgenic Nicotiana benthamiana Domin. leaves to excise the bar selectable marker gene. The bar free tissues, in the presence of the nucleoside analogue ribavirin, were then used to regenerate plants free of virus and the selectable marker.

- Intragenomic relocation of transgenes via transposable elements: Transposable elements are DNA sequences that have the ability to move within the genome. Systems have been developed based on the $A c / D s$ transposable element. Chimeric $D s$ with a marker are inserted into the plant along with the Ac transposase. Ac expression allows the marker to transpose to a new genomic location and then be segregated away in subsequent generations (Miki and McHugh, 2004). The need for segregation makes the Ac/Ds system unsuitable for vegetatively propagated crops (Goldsbrough, 2001).

- MAT (multi-auto-transformation) system: The ipt gene from Agrobacterium tumefaciens encodes for isopentenyl phosphotransferase. The protein catalyzes a reaction important to the formation of cytokinins. The resulting cytokinins induce abnormal organogenesis within the transformed tissue. The sectors containing the resulting plant shoots are proliferated. In the MAT system, the ipt gene is then eliminated via a linked $A c / D s$ transposition as described above and marker-free, normal plants are recovered. The frequency of recovery is low but new systems hold promise to increase the efficiency (Aragão and Brasileiro, 2002).
- D-Amino acid metabolism: Enzymes for metabolism of D-enantiomers of amino acids are found in many eukaryotes but have not been reported in plants. Some D forms of amino acids such as D-alanine and D-serine are toxic to some plants. Introducing either of the genes, daol from Rhodotorula gracilis (Alonso et al., 1998) encoding D-Amino acid oxidase (DAAO), [EC 1.4.3.3] or the dsdA gene from $E$. coli encoding D-serine ammonialyase [EC:4.3.1.18] can mitigate the toxic effects (Erikson et al., 2003). The unique feature of this system is that it can be used as a positive or negative selection system depending on the additives to the medium. Marker-free plants can be produced by first transforming with the doal gene and selecting on D-serine or D-alanine. Following sexual reproduction, segregating seedlings can be screened in vitro by growing on $\mathrm{D}$-valine or $\mathrm{D}$-isoleucine which are non-toxic to wild type plants but are converted into toxins in the doal positive plants. Surviving plants are doal negative and either gene of interest negative or positive (Erikson et al., 2004).

\section{CONCLUSION}

Cassava is grown only in the tropics, where it is used primarily as a subsistence crop in developing countries. It is an important source of calories for large portions of the population in many of these countries, especially in Africa. Clearly, the biosafety concerns of a broad range of stakeholders must be taken into account in the development of transgenic cassava. At the same time, the geographic restriction and role of cassava dictate that crop improvement research will most often be undertaken by public sector scientists, who may be working with very limited resources. Thus, the choice of transgenes to be introduced, including marker genes for selection of successful transformation events, must be carefully considered not only from the standpoints of food and feed safety and environmental impact, but also for efficiency and ease of use, so that limited research funding may be conserved.

Marker-free transformation systems that are currently available have not yet been thoroughly evaluated for biosafety. Of the scorable markers currently in use, only the uidA gene has been extensively evaluated and approved in commercially-available transgenic crops, and may thus be considered as safe. More limited data are available on the characteristics of either the luc or $g f p$ genes, although their risk appears to be minimal. Based on extensive use and a wealth of publicly available scientific 
Review: Biosafety considerations for selectable and scorable markers used in cassava biotechnology

and governmental reviews, the selectable markers $n p t I I$, $h p t$, bar, and manA have little risk in terms of food and feed safety or environmental impact. These selectable markers represent the safest, most efficient and most cost effective options for use in cassava biotechnology at this time.

\section{ACKNOWLEDGEMENT}

This report was written on the request of the International Center for Tropical Agriculture (CIAT) on behalf of the Cassava Biotechnology Network - a network of national agricultural research institutes, international centers, and advanced laboratories from around the world that are engaged in cassava biotechnology. We would like to acknowledge the assistance of Mr. Paul Chavarriaga of CIAT, Dr. Nigel Taylor of the Donald Danforth Plant Science Center, and Mr. Lawrence Kent of the Program for Biosafety Systems (PBS) for reviewing earlier drafts and providing suggestions for improvements.

This paper was prepared on behalf of the Regulatory Approval Strategies Component of PBS, which is funded by the United States Agency for International Development. The Regulatory Approval Strategies Component is managed by the Donald Danforth Plant Science Center under sub-agreement EEM-A-00-0300001-00-(DDPSC)-2826-30X with the International Food Policy Research Institute, which manages the overall PBS Program.

Received May 17, 2005; accepted September 24, 2005.

\section{REFERENCES}

Advisory Committee on Releases to the Environment's (ACRE's) response to concerns raised in written representations and submissions associated with the CHARDON LL public hearing and to statements made at ACRE's open hearing relating to the safety assessment of T25 GM maize conducted under Directive 90/220/EEC. (2002) http://www.defra.gov.uk/environment/acre/advice/pdf/ acre_advice20.pdf

Alonso J, Barredo JL, Diez B, Mellado E, Salto F, Garcia JL, Cortes E (1998) D- Amino-acid oxidase gene from Rhodotorula gracilis (Rhodosporidium toruloides) ATCC 26217. Microbiology 144: 1095-1101

Aragão FJL, Brasileiro ACM (2002) Positive, negative and marker-free strategies for transgenic plant selection. Braz. J. Plant Physiol. 14: 1-10
Astwood JD, Fuchs RL (1996) Allergenicity of foods derived from transgenic plants. In Wuthrich B, Ortolani C, eds, Highlights in Food Allergy, Monogr. Allergy 32: 105-120

Australia New Zealand Food Authority (2001) Food derived from insect protected (New Leaf ${ }^{\circledR}$ ) Potato lines BT-06, ATBT04-06, ATBT04-31, ATBT04-36, and SPBT02-05; A Safety Assessment. Technical Report Series No. 11

Beck E, Ludwig G, Auerswald EA, Reiss B, Schaller H (1982) Nucleotide sequence and exact localization of the neomycin phosphotransferase gene from transposon Tn5. Gene 9: 327-336

Bevan MW, Flavell RB, Chilton M-D (1983) A chimaeric antibiotic resistance gene as a selectable marker for plant cell transformation. Nature 304: 184-187

Brasileiro ACM, Aragão FJL (2001) Marker genes for in vitro selection of transgenic plants. J. Plant Biotechnol. 3: 113-121

Canadian Food Inspection Agency, Plant Health and Production Division, Decision Document DD98-28 (1998) Determination of the Safety of AgrEvo Canada Inc.'s Glufosinate Ammonium Herbicide-Tolerant Brassica rapa Canola Line HCR-1. http://www.inspection.gc.ca/english/ plaveg/bio/dd/dd9828e.shtml

Canadian Food Inspection Agency, Plant Products Directorate Plant Biosafety Office, Decision Document DD2004-49 (2004) Determination of the Safety of Bayer CropScience's Herbicide Tolerant LibertyLink ${ }^{\circledR}$ Cotton Event LLcotton25 (Gossypium hirsutum L.). http:// www.inspection.gc.ca/english/plaveg/bio/dd/dd0449e.shtml

Cellini F, Chesson A, Colquhoun I, Constable A, Davies HV, Engel KH, Gatehouse AMR, Karenlampi S, Kok EJ, Leguay J-J, Lehesranta S, Noteborn HPJM, Pedersen J, Smith M (2004) Unintended effects and their detection in genetically modified crops. Food Chem. Toxicol. 42: 10891125

Chalfie M (1995) Green Fluorescent Protein. Photochem. Photobiol. 62: 651-656

Chalfie M, Tu Y, Euskirchen G, Ward WW, Prasher DC (1994) Green fluorescent protein as a marker for gene expression. Science 263: 802-805

Chavarriaga P (2005) Personal communication

Codex Alimentarius Commission Alinorm 03/34, Joint FAO/ WHO Food Standard Programme Codex Alimentarius Commission, Twenty-fifth session, Rome Italy (2003) Report of the Third Session of the CODEX Ad Hoc Intergovernmental Task Force on Foods Derived From Biotechnology, Yokohama, Japan 4-8 March 2002. Appendix IV:57-60. http://www.codexalimentarius.net/ download/report/46/A10334ae.pdf

DeBlock M, De Brower D, Tenning P (1989) Transformation of Brassica napus and Brassica oleracea using Agrobacterium tumefaciens and the expression of the bar and neo genes in the transgenic plants. Plant Physiol. 91: 694-701

de Vetten N, Wolters AM, Raemakers K, van der Meer I, ter Stege R, Heeres E, Heeres P, Visser R (2003) A transformation method for obtaining marker-free plants of a 
cross-pollinating and vegetatively propagated crop. Nat. Biotechnol. 21: 439-442

Environmental Protection Agency (EPA) (1997) Phosphinothricin Acetyltransferase and the Genetic Material Necessary for Its Production in All Plants; Exemption from the Requirement of a Tolerance on All Raw Agricultural Commodities. Federal Register 62: 17717-17720

Environmental Protection Agency (EPA) (2004a) Hygromycin B phosphotransferase; exemption from the requirement of a tolerance. Federal Register 69: 18275-18278

Environmental Protection Agency (EPA) (2004b) Phosphomannose Isomerase and the Genetic Material Necessary for Its Production in All Plants; Exemption from the Requirement of a Tolerance. Federal Register 69: 26770-26775

Erikson O, Clapham D, Hertzberg M, Näsholm T (2003) DAmino acid selectable markers. Online abstract at http:// www.treebiotech2003.norrnod.se/s2_o.htm accessed 1/27/ 2005

Erikson O, Hertzberg M, Näsholm T (2004) A conditional marker gene allowing both positive and negative selection in plants. Nat. Biotechnol. 22: 455-458

European Federation of Biotechnology (2001) Antibiotic resistance markers in genetically modified GM crops. Briefing Paper 10 http://www.efbweb.org/public/ pubview.htm site access 12/16/2004

European Food Safety Authority (2004) Opinion of the Scientific Panel on Genetically Modified Organisms on the use of antibiotic resistance genes as marker genes in genetically modified plants (Question N EFSA-Q-2003-109) Opinion adopted on 2 April 2004 The EFSA Journal 48:1-18

Food and Drug Administration (1994) "Secondary Food Additives Permitted in Food for Human Consumption; Food Additives Permitted in Feed and Drinking Water of Animals; Aminoglycoside 3'-Phosphotransferase II; Final Rule." Federal Register 59:26700-26711

Food and Drug Administration Center for Food Safety and Applied Nutrition Office of Premarket Approval (1998) Guidance for Industry: Use of Antibiotic Resistance Marker Genes in Transgenic Plants Draft Guidance. http:// vm.cfsan.fda.gov/ dms/opa-armg.html

Food Standards Australia New Zealand (2002) Final assessment report application A436. Oil and linters derived from insect protected cotton containing event 15985. http:// www.foodstandards.gov.au/standardsdevelopment/ applications/applicationa436insectprotectedcotton/ a436farexecsummary211633.cfm

Fraley RT, Rogers SG, Horsch RB, Sanders PR, Flick JS, Adams SP, Bittner ML, Brand LA, Fink CL, Fry JS, Gallupi GR, Goldberg SB, Hoffman NL, Woo SC (1983) Expression of bacterial genes in plant cells. Proc. Natl. Acad. Sci. (USA) 80: 4803-4807

Fregene M, Puonti-Kaerlas J (2002) Cassava Biotechnology. In Hillocks RJ, Thresh JM, Bellotti AC, eds, Cassava: Biology, Production and Utilization, CAB International, pp 179-207
Fuchs RL, Ream JE, Hammond BG, Naylor MW, Leimgruber RM, Berberich SA (1993) Safety assessment of the neomycin phosphotransferase II (NPTII) protein. Biotechnology 11: 1543-1547

Gilissen LJW, Metz PLJ, Stiekema WJ, Nap JP (1998) Biosafety of $E$. coli $\beta$-glucuronidase (GUS) in plants. Transgenic Res. 7: 157-163

Goldsbrough A (2001) Methods for avoidance and removal of selectable marker genes in crop transformation systems. http://www.defra.gov.uk/environment/acre/uti/08.htm

González AE, Schöpke C, Taylor NJ, Beachy RN, Fauquet CM (1998) Regeneration of transgenic cassava plants (Manihot esculenta Crantz) through Agrobacterium-mediated transformation of embryogenic suspension cultures. Plant Cell Rep. 17: 827-831

Gritz L, Davies J (1983) Plasmid-encoded hygromycin B resistance: the sequence of hygromycin B phosphotransferase gene and its expression in Escherichia coli and Saccharomyces cerevisiae. Gene 25: 179-188

Hails RS (2000) Genetically modified plants - The debate continues. Trends Ecol. Evol. 15: 14-18

Haseloff J, Amos B (1995) GFP in Plants. Trends Genet. 11: 328-329

Haslberger AG (2003) Codex Guidelines for GM Foods Include the Analysis of Unintended Effects. Nat. Biotechnol. 21: 739-741

Herrera-Estrella L, De Block M, Messens E, Hernalsteen JP, Van Montagu M, Schell J (1983) Chimeric genes as dominant selectable markers in plant cells. EMBO J. 2: 987995

Information Systems for Biotechnology, Field Test Releases in the U.S. Updated 12/22/2004 http://www.isb.vt.edu/ cfdocs/fieldtests1.cfm accessed 12/27/2004

Jefferson RA (1989) The GUS reporter gene system. Nature 342: $837-838$

Jelenic S (2003) Kanamycin Resistance Marker Gene in Transgenic Plants. Food Technol. Biotechnol. 41: 183-190

Jennings DL, Iglesias C (2002) Breeding for Crop Improvement. In Hillocks RJ, Thresh JM, Bellotti AC, eds, Cassava: Biology, Production and Utilization, CAB International, pp 149-166

Jones DD, Maryanski JH (1991) Safety considerations in the evaluation of transgenic plants for human food. In Levin MA, Straus HS, eds, Risk Assessment in Genetic Engineering, New York: McGraw-Hill, pp 64-82

Kärenlampi S (1996) Health Effects of Marker Genes in Genetically Engineered Food Plants. TemaNord 530. The Nordic Council of Ministers. Store Standstræde 18. DK-1255 Copenhagen K, pp 7-66

Kopertekh L, Jüttner G, Schiemann J. (2004) PVX-Cremediated marker gene elimination from transgenic plants. Plant Mol. Biol. 55: 491-500

Kuhstoss S, Rao RN (1983) Expression in Streptomyces ambofaciens of an Escherichia coli K-12 gene which confers resistance to hygromycin B. Gene 26: 295-299 
Review: Biosafety considerations for selectable and scorable markers used in cassava biotechnology

Laminski S, Gray VM, Mycock DJ, Blatch GL, Groll J, Rey MEC (2002) Green fluorescent protein as a reporter of early transformation in Cassava (Manihot esculenta Crantz). South African J. Sci. 98: 301-303

Leboul J, Davies J (1982) Enzymatic modification of hygromycin B in Streptomyces hygroscopicus. J. Antibiot. 35: $527-528$

Li HQ, Sautter C, Potrykus I, Pounti-Kaerlas J (1996) Genetic transformation of cassava (Manihot esculenta Crantz). Nat. Biotechnol. 14: 736-740

Malpartida F, Zalacain M, Jimenez A, Davies J (1983) Molecular cloning and expression in Streptomyces lividans of a hygromycin B phosphotransferase gene from Streptomyces hygroscopicus. Biochem. Biophys. Res. Commun. 117: 6-12

Marker Genes Technologies, Inc., Live cell luciferase assay kit - Product Mo626 Product Information Sheet (0626-005). http://www.markergene.com/

Matthews P, Fieg S, Gubler F, McCallum G, McCarthy N, Thornton S, Wang M, Jacobsen J (1999) Transgene Segregation to Obtain Selectable Marker-Free Transformed Barley. Proceedings of the 9th Australian Barley Technical Symposium. http://www.regional.org.au/au/abts/1999/matthews. htm?PHPSESSID=ec4a0c42626ab4dc068f9be832936974\#P $0 \_0$

Miki B, McHugh S (2004) Selectable marker genes in transgenic plants: applications, alternatives and biosafety. $J$. Biotechnol. 107: 193-232

Miles JS, Guest JR (1984) Nucleotide sequence and transcriptional start point of the phosphomannose isomerase gene (manA) of Escherichia coli. Gene 32: 41-48

Millar AJ, Short SR, Hiratsuka K, Chua NH, Kay SA (1992) Firefly luciferase as a reporter of regulated gene expression in higher plants. Plant Mol. Biol. Rep. 10: 324-337

Monsanto Company web site: http://www.monsanto.com/ monsanto/content/sci_tech/prod_safety/bollgard_II/pss.pdf August 2003 accessed 12/23/2004

Nap JP, Bijvoet J, Stiekema WJ (1992) Biosafety of kanamycin-resistant transgenic plants. Transgenic Res. 1: 239-249

National Academy of Sciences (NAS) (2000) Genetically modified pest-protected plants: Science and regulation, Washington D.C.: National Academy Press

National Academy of Sciences (NAS) (2002) Environmental effects of transgenic plants, Washington D.C.: National Academy Press

OECD Environmental Health and Safety Publications Series on Harmonization of Regulatory Oversight in Biotechnology No. 11 (1999) Consensus Document on General Information Concerning the Genes and Their Enzymes that Confer Tolerance to Phosphinothricin Herbicide. http://www.olis.oecd.org/olis/1999doc.nsf/LinkTo/ env-jm-mono(99)13

Office of the Gene Technology Regulator (2003) Risk Assessment and Risk Management Plan Application for license for dealings involving intentional release of a genetically modified organism into the environment. DIR 034/2003 Title: Field Trial of Genetically Modified Cotton (Gossypium hirsutum) Expressing an Insecticidal Gene (vip3A) http://www.ogtr.gov.au/pdf/ir/dir034.pdf

Olsen KM, Schaal BA (1999) Evidence on the origin of cassava: Phylogeography of Manihot esculenta. Proc. Natl. Acad. Sci. (USA) 96: 5586-5591

Ouakfaoui S, Miki B (2005) The stability of the Arabidopsis transcriptome in transgenic plants expressing the marker genes nptII and uidA. Plant J. 41: 791-800

Ow DW (2002) Recombinase-directed plant transformation for the post-genomic era. Plant Mol. Biol. 48: 183-200

Ow DW, Wood KV, DeLuca M, De Wet JR, Helinski DR, Howell SH (1986) Transient and stable expression of the firefly luciferase gene in plant cells and transgenic plants. Science 234: 856-859

Pang S-Z, DeBoer D, Wan Y, Ye G, Layton JC, Neher MK, Armstrong CL, Fry JE, Hinchee MAW, Fromm ME (1996) An improved Green Fluorescent Protein gene as a vital marker in plants. Plant Physiol. 112: 893-900

Pardo JM, Malpartida F, Rico M, Jimenez A (1985) Biochemical basis of resistance to hygromycin B in Streptomyces hygroscopicus - the producing organism. J. Gen. Microbiol. 131: 1289-1298

Privalle LS (2002) Phosphomannose isomerase, a novel plant selection system: potential allergenicity assessment. Ann. N. Y. Acad. Sci. 964: 129-138

Privalle LS, Wright M, Reed J, Hansen G, Dawson J, Dunder EM, Chang Y-F, Powell ML, Meghji M (2000) Phosphomannose Isomerase, A Novel Selectable Plant Selection System: Mode of Action and Safety Assessment. In Fairbairn C, Scoles G, McHughen A, eds, Proceedings of the 6th International Symposium on The Biosafety of Genetically Modified Organisms, Saskatoon, Canada, University Extension Press, Univ. Saskatchewan, pp 171-178

Raemakers CJJM, Sofiari E, Taylor N, Henshaw G, Jacobsen E, Visser RGF (1996) Production of transgenic cassava (Manihot esculenta Crantz) plants by particle bombardment using luciferase activity as selection marker. Mol. Breed. 2: 339-349

Raemakers CJJM, Sofiari E, Jacobsen E, Visser RGF (1997) Regeneration and transformation of cassava. Euphytica 96: 153-161

Raemakers K, Schreuder M, Pereira I, Munyikwa T, Jacobsen E, Visser R (2001) Progress made in FEC transformation of cassava. Euphytica 120: 15-24

Rao RN, Allen NE, Hobbs JN Jr., Alborn WE Jr., Kirst HA, Paschal JW (1983) Genetic and enzymatic basis of hygromycin B resistance in Escherichia coli. Antimicrob. Agents Chemother. 24: 689-695

Redenbaugh K, Hiatt W, Martineau B, Lindemann J, Emlay D (1994) Aminoglycoside 3'-phosphotransferase II (APH (3') II): Review of its safety and use in the production of genetically engineered plants. Food Biotechnol. 8: 137165 
Reed J, Privalle LS, Powell ML, Meghji M, Dawson J, Dunder E, Suttie J, Wenke A, Launis K, Kramer C, Chang YF, Hansen G, Wright M (2001) Phosphomannose isomerase: An efficient selectable marker for plant transformation. In Vitro Cell. Dev. Biol. Plant 37: 127-132

Richards HA, Han CT, Hopkins RG, Failla ML, Ward WW, Stewart CN (2003) Safety assessment of recombinant green fluorescent protein orally administered to weaned rats. $J$. Nutr. 133: 1909-1912

Sarria R, Torres E, Angel F, Chavarriaga P, Roca WM (2000) Transgenic plants of cassava (Manihot esculenta) with resistance to Basta obtained by Agrobacterium-mediated transformation. Plant Cell Rep. 19: 339-344

Schöpke C, Taylor N, Carcamo R, Konan NK, Marmey P, Henshaw GG, Beachy RN, Fauquet CM (1996) Regeneration of transgenic cassava plants (Manihot esculenta Crantz) from microbombarded embryogenic suspension cultures. Nat. Biotechnol. 14: 731-735

Siritunga D, Sayre RT (2003) Generation of cyanogen-free transgenic cassava. Planta 217: 367-373

Sjoblad RD, McClintock JT, Engler R (1992) Toxicological considerations for protein components of biological pesticide products. Regul. Toxicol. Pharmacol. 15: 3-9

Smalla K, Borin S, Heuer H, Gebhard F, van Elsas JD, Nielsen K (2000) Horizontal transfer of antibiotic resistance genes from transgenic plants to bacteria - are there new data to fuel the debate? In Fairbairn C, Scoles G, McHughen A, eds, Proceedings of the 6th International Symposium on The biosafety of genetically modified organisms, Saskatoon, Canada, University Extension Press, Univ. Saskatchewan, pp 146-154

Stewart CN, Richards HA, Halfhill MD (2000) Transgenic Plants and Biosafety: Science, Misconceptions and Public Perception. Biotechniques 29: 832-843

Taylor N (2005) Personal communication

Taylor N, Chavarriaga P, Raemakers K, Siritunga D, Zhang P (2004) Development and application of transgenic technologies in cassava. Plant Mol. Biol. 56: 671-688
Taylor SL, Lemanske RF, Bush RK, Busses WW (1987) Food Allergens: Structure and Immunologic Properties. Ann. Allergy 59: 93-99

Thompson CJ, Movva NR, Tizard R, Crameri R, Davies JE, Lauwereys M, Botterman J (1987) Characterization of the herbicide-resistance gene bar from Streptomyces hygroscopicus. EMBO J. 6: 2519-2523

Van den Eede G, Aarts H, Buhk H-J, Corthier G, Flint HJ, Hammes W, Jacobsen B, Midvedt T, Van der Vossen J, von Wright A, Wackernagel W, Wilcks A (2004). The relevance of gene transfer to the safety of food and feed derived from GM plants. Food Chem. Toxicol. 42: 1127-1156

Waldron C, Murphy EB, Roberts JL, Gustafson GD, Armour SL and Malcom SK (1985) Resistance to hygromycin B - a new marker for plant transformation studies. Plant

Mol. Biol. 5: 103-108

Westby A (2002) Cassava utilization, storage and small-scale processing. In Hillocks RJ, Thresh JM, Bellotti AC, eds, Cassava: Biology, Production and Utilization, CAB International, pp 281-300

Wohlleben W, Arnold W, Broer I, Hilleman D, Struach E, Puhler A (1988) Nucleotide sequence of the phosphinothricin $\mathrm{N}$-acetyltransferase gene from Streptomyces viridochromogenes Tu494 and its expression in Nicotiana tabacum. Gene 70: 25-37

Wolfenbarger LL, Phifer PR (2000) The ecological risks and benefits of genetically engineered plants. Science 290: 20882093

World Health Organization (1993) Health aspects of marker genes in genetically modified plants: report of a WHO workshop, WHO/FNU/FOS/93.6

Zhang P, Legris G, Coulin P, Puonti-Kaerlas J (2000a) Production of stably transformed cassava plants via particle bombardment. Plant Cell Rep. 19: 939-945

Zhang P, Potrykus I, Puonti-Kaerlas J (2000b) Efficient production of transgenic cassava using negative and positive selection. Transgenic Res. 9: 405-415 